\title{
CD133 glycosylation is enhanced by hypoxia in cultured glioma stem cells
}

\author{
KRISTINA S. LEHNUS ${ }^{1}$, LAURA K. DONOVAN ${ }^{1}$, XIAOWEI HUANG ${ }^{2}$, NINGHUI ZHAO $^{3}$, \\ TRACY J. WARR ${ }^{4}$, GEOFFREY J. PILKINGTON ${ }^{1}$ and QIAN AN ${ }^{1}$
}

\begin{abstract}
${ }^{1}$ Cellular and Molecular Neuro-Oncology Research Group, Institute of Biomedical and Biomolecular Science, School of Pharmacy and Biomedical Sciences, University of Portsmouth, Portsmouth, UK; ${ }^{2}$ Laboratory of Conservation and Utilization for Bio-resources, Yunnan University; ${ }^{3}$ Department of Neurosurgery, The Second Hospital Affiliated to

Kunming Medical College, Kunming, Yunnan, P.R. China; ${ }^{4}$ Brain Tumour UK Neuro-oncology Research Group, Research Institute in Healthcare Sciences, School of Applied Sciences, University of Wolverhampton, Wolverhampton, UK
\end{abstract}

Received September 4, 2012; Accepted October 17, 2012

DOI: 10.3892/ijo.2013.1787

\begin{abstract}
The cancer stem cell (CSC) marker CD133 is widely expressed in gliomas and employed mostly by use of the CD133/1 antibody which binds the extracellular glycosylated $\mathrm{AC} 133$ epitope. CD133 recognition may, however, be affected by its glycosylation pattern and oxygen tension. The present study investigates the effect of oxygen deprivation on CD133 expression and glycosylation status employing a high AC133-expressing glioblastoma multiforme (GBM) cell line, IN699. IN699 cells were cultured under normoxic $\left(21 \% \mathrm{O}_{2}\right)$ and hypoxic $\left(3 \% \mathrm{O}_{2}\right)$ conditions. CD133 expression was analysed by western blotting (WB), qRT-PCR, immunocytochemistry (ICC) and flow cytometry using the glycosylation-specific antibody CD133/1 and ab19898 which binds the unglycosylated intracellular residues of CD133. By flow cytometry, ab19898 detected 94.1\% and $96.2 \% \mathrm{CD}^{2} 33^{+}$cells under normoxia and hypoxia, respectively. Hypoxia significantly increased the percentage of $\mathrm{CD}_{133^{+}}$cells from $69 \%$ to $92 \%$ using CD133/1 ( $\left.<<0.005\right)$. Moreover, a significantly higher geomean fluorescence intensity (GMI) was demonstrated by ab19898 ( $\mathrm{p}<0.005)$ in $\mathrm{CD} 133^{+}$cells WB and qRT-PCR results were consistent with flow cytometry data. Furthermore, over a period of 72-h incubation under normoxic and hypoxic conditions after autoMACS sorting, an average of $31.8 \%$ and $42.2 \%$, respectively, of CD133-negative IN699 cells became positive using CD133/1. Our data show that a) previously reported CD133- cells may have been misidentified using the glycosylation-specific CD133/1 as constitutive expression of CD133 was detected by the intracellular antibody ab19898; b) hypoxia promotes glycosylation status of CD133, indicating possible involvement of glycosylated CD133 in the process of anti-hypoxia-mediated apoptosis.
\end{abstract}

Correspondence to: Dr Qian An, School of Pharmacy and Biomedical Sciences, University of Portsmouth, St Michael's Building, White Swan Road, Portsmouth PO1 2DT, UK

E-mail: qian.an@port.ac.uk

Key words: CD133, cancer stem cell, glycosylation, hypoxia, glioma

\section{Introduction}

CD133 was first presented as a key marker for brain tumour stem cells (BTSCs) in 2003 when in vitro experiments indicated that $\mathrm{CD} 133^{+}$cells possess significantly enhanced ability to differentiate, proliferate and self-renew. The research also showed $\mathrm{CD}_{133^{+}}$cells could generate new malignancies that were phenotypically and histologically similar to the tumour of origin (1). However, since these findings were published, other researchers have been able to demonstrate tumourigenesis by CD133- cells and challenged the role of CD133 in tumour initiation $(2,3)$. Despite the controversy, the link between CD133 and tumourigenesis has remained a 'hot' topic in CSC research (4-6). Current evidence also indicates that CD133 expression in CSCs differs according to cell cycle phases in vitro, although stem cell potency and differentiating capabilities are preserved (7). Indeed, CD133 expression, and thus perhaps also glycosylation, fluctuates during the cell cycle, being low in quiescent cells in G0 or G1 but higher in subsequent phases (7). This has important implications for using CD133 to enrich CSCs as non-dividing invading cells and other quiescent cells within the tumour mass could be missed by immunological detection of CD133.

Several splice variants of CD133 have been identified in man (8). This has potential impact on the CSC detection as CD133 may be present but lacking the antibody specific epitope so cells could be described falsely as CD133. Indeed, it has been reported that $\mathrm{CD} 133^{-}$glioblastoma cells (determined by CD133/1 antibody) express a truncated variant of the protein (9). Post-translational glycosylation of CD133 may also affect antibody detection since the commonly used antibody, CD133/1, is likely to detect CD133-expressing cells only when the epitope AC133 is glycosylated, causing concerns over the limitations of glycosylated CD133 epitopes in isolating CSCs (10). Furthermore, the role of CD133 in brain tumour biology must be elucidated with consideration of the tumour microenvironment. Hypoxic microenvironment is a feature of glioblastoma multiforme (GBM), the most common and malignant of primary glial tumours in the brain (11). Hypoxia is believed to trigger BTSC proliferation and invasion as 
well as to promote resistance to therapy $(12,13)$. It has been demonstrated by us and others, using the CD133/1 antibody, that CD133 expression increases under hypoxic culture conditions (14-17), suggesting a similar CD133 expression pattern in vivo. A recent study shows that enhanced expression of OCT3/4 (octamer-binding transcription factor 3/4) and SOX2 (SRY-box containing gene 2) by HIF-1 $\alpha$ (hypoxia-inducible factor $1 \alpha$ ) and HIF-2 $\alpha$ (hypoxia-inducible factor $2 \alpha$ ) is required for hypoxia-induced CD133 expression in cultured human lung cancer cells (18). The study also reveals the direct binding of OCT4 and SOX2 to the P1 promoter of CD133 gene, further elucidating the underlying mechanism since P1 is most strongly associated with hypoxia-induced promoter activity of CD133 transcription (18). However, although it is widely accepted that hypoxia enhances CD133 expression, it is not yet well understood how the immunodetection of CD133 may be affected by oxygen tension. A recent study demonstrates inconsistent CD133 immunostaining patterns in glioblastoma tissues using four different antibody clones, reflecting different binding sites as well as glycosylation status. Yet the implication of normoxic and hypoxic $\mathrm{CD}_{133^{+}}$niches remains unclear (19). In this research we set out to investigate the possibility that CD133 glycosylation might be influenced by different oxygen tensions and that this may, in turn, determine the true expression of CD133 in glioma-derived cell populations.

We have previously reported the biological and molecular characteristics of one unique paediatric GBM cell line, IN699, which contains an unusually high population of CD133-positive cells, where parent culture and the $\mathrm{CD} 133^{+} / \mathrm{CD} 133^{-}$subpopulations derived therefrom under normoxic and hypoxic culture conditions were subject to thorough investigation (14). Our data from immunocytochemistry and flow cytometry using neural stem cell specific antigenic markers indicate similar stemness and differentiation capacities of both $\mathrm{CD}_{133^{+}}$and $\mathrm{CD}_{133^{-}}$cells Molecular cytogenetic study also shows identical genomic imbalances between $\mathrm{CD}_{133^{+}}$and CD133- fractions. Under hypoxic conditions, $\mathrm{CD} 133^{+}$cells demonstrated a significantly enhanced proliferative rate whereas a significant increase in invasive propensity was observed in the CD133- cells. Furthermore, hypoxia promoted CD133 expression associated with phenotype of poorly differentiated cells with cancer stem cell markers (14). In the present study, we further investigated whether CD133 glycosylation was regulated by changes in oxygen tension and how hypoxia might affect the immunodetection of CD133. Using western blotting (WB), flow cytometry and immunocytochemistry (ICC), changes in CD133 expression and glycosylation under normoxic and hypoxic conditions were demonstrated by CD133/1 and another commercially available CD133 antibody (ab19898, see below) in early passage biopsyderived IN699 cells.

\section{Materials and methods}

Cell line. IN699 cells (passages 14-19) known to contain a high proportion of CD133/1 $1^{+}$cells were used in this study (14). Cells were cultured in Neurobasal-A medium (Fisher Scientific, Loughborough, UK) with supplements under normoxic $(21 \%$ oxygen) and hypoxic (3\% oxygen) conditions as described in previous studies $(14,20)$. Cells were grown to $90 \%$ confluency before experimental use.
Antibodies

Primary antibodies. Ab19898 (Abcam, Cambridge, UK) recognises the intracellular unglycosylated amino acid residues 848-865 of CD133 near the C-terminus. It was used in WB $(1: 100)$, ICC $(1: 200)$ and flow cytometry $(1: 100)$ to investigate the presence of the CD133 protein.

CD133/1 (W6B3C1) pure for WB (1:200) and CD133/1 (AC133) pure for ICC (1:200) and flow cytometry (1:50) were purchased from Miltenyi-biotec Ltd. (Surrey, UK). Both antibodies recognise the glycosylated amino acid residues 508-792 on the extracellular loops of CD133. They were used to detect changes in CD133 glycosylation under normoxic and hypoxic conditions. The binding sites of both CD133 primary antibodies are illustrated in Fig. 1. Anti-actin (Sigma-Aldrich, Dorset, UK) was used as a control in the WB experiment (1:1000).

Secondary antibodies. Horseradish peroxidase (HRP)conjugated IgG (Invitrogen/Life Technologies Ltd., Paisley, UK) was used for chemiluminescent detection in WB (1:1000). Fluorochrome-conjugated AlexaFluor-488 and -568 (Invitrogen/ Life Technologies Ltd.) were used in flow cytometry (1:500) and ICC (1:500).

Western blotting (WB). Western blotting was performed according to standard protocol. Briefly, cell lysates $(20 \mu \mathrm{g}$ of protein) from normoxic and hypoxic IN699 cells were separated in the 'any kDa' pre-cast gel (Bio-Rad Laboratories Ltd., Hemel Hempstead, UK) and transblotted onto a polyvinylidene difluoride membrane (GE Healthcare Life Sciences, Little Chalfont, UK). Proteins were detected using the corresponding primary antibody and horseradish peroxidase-linked secondary antibodies; the blot was visualized by chemiluminescence (Interchim SA/Cheshire Sciences Ltd., Chester, UK) with the GBOX Chemi XT16 software (Syngene, Cambridge, UK).

Quantitative real-time PCR ( $q R T-P C R)$. The mRNA level of CD133 in IN699 cells (normoxic and hypoxic) was quantified by qRT-PCR using TaqMan Gene Expression Assay with predesigned probe spanning the exon 9-10 junction, which detects all CD133 transcript variants reported in humans (8). The assay was performed on the ABI 7500 Real-Time PCR System (Applied Biosystems/Life Technologies Ltd.). The expression of CD133 was normalised to that of the endogenous gene, $\beta$-actin, served as an internal control. The relative quantification of $C D 133$ in normoxic and hypoxic IN699 cells was carried out using the $2^{-\Delta \Delta C t}$ method (21).

ICC. ICC was carried out following established procedure in our laboratory (14). For the intracellular antibody (ab19898) detection, cells were permeabilised with $0.02 \%$ Triton X-100 (Sigma-Aldrich) at $4^{\circ} \mathrm{C}$ for $10 \mathrm{~min}$. Permeabilised and nonpermeabilised cells were then incubated with the relevant primary antibody (ab19898 and CD133/1) at room temperature for $1 \mathrm{~h}$, following another 30-min incubation with the corresponding secondary antibody. Hoechst Blue (1:200) (Sigma-Aldrich) nuclear counterstain was added to each well and the coverslips were then mounted on microscope slides with a small drop of VectorShield mounting medium (Vector Laboratories Ltd., Orton Southgate, UK). The slides were observed using a Zeiss Axio Imager Epifluorescence micro- 


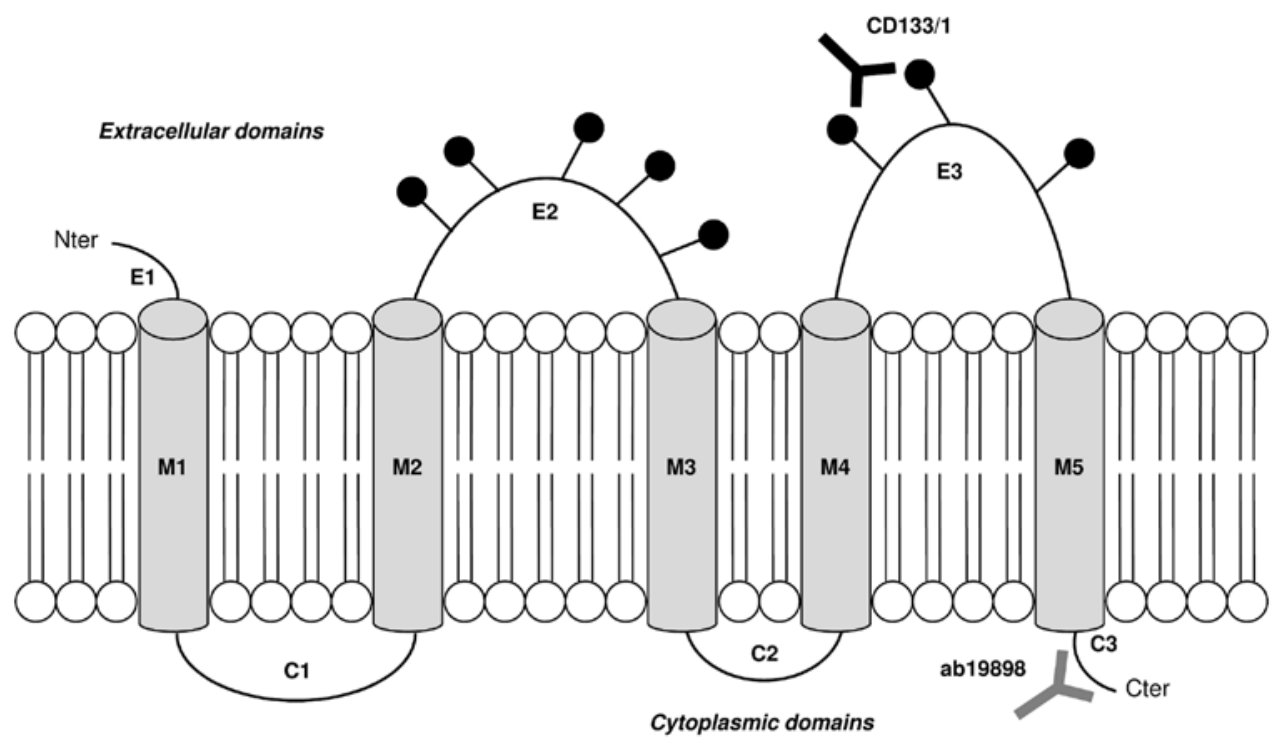

Figure 1. Illustration of the binding sites of CD133/1 and ab19898 [modified from Taïeb et al (25)]. Glycosylation sites are indicated by black circles. E1-3, extracellular loops; M1-5, transmembrane domains; C1-3, intracellular loops.

scope (Carl Zeiss Ltd., Welwyn Garden City, UK). Images were captured using Velocity software (V5.2, Perkin-Elmer, Cambridge, UK).

Flow cytometry. Flow cytometry was performed with CD133/1 and ab19898 in three independent experiments as described previously (14). For the extracellular primary antibody CD133/1, normoxic and hypoxic IN699 cells were incubated with $\mathrm{CD} 133 / 1$ at $4^{\circ} \mathrm{C}$ for 30 min excluding the control samples. Then the anti-mouse secondary antibody AlexaFluor- 488 was added to all samples and the cells were incubated at $4^{\circ} \mathrm{C}$ for another $15 \mathrm{~min}$. After incubation the cells were resuspended in $1 \%$ goat serum/PBS (Sigma-Aldrich) and transferred to fluorescence-activated cell sorting (FACS) tubes. The analysis was carried out on a FACSCalibur (BD Bioscience, Oxford, UK) and propidium iodide (PI) (Sigma-Aldrich) was added to each tube shortly before analysis in order to enable cell viability correction. For the intracellular primary antibody ab19898, cells were permeabilised with Cytofix/Cytoperm ${ }^{\mathrm{TM}}$ (BD Bioscience) at $4^{\circ} \mathrm{C}$ for $20 \mathrm{~min}$ before adding ab19898. The remaining steps were identical to those for the non-permeabilised cells, except that no PI was added prior to visualisation.

Automated magnetic cell sorting (autoMACS). CD133-expressing cells were sorted using the automated magnetic cell sorting system (autoMACS ${ }^{\mathrm{TM}}$ ) (Miltenyi Biotec) (14). Briefly, IN699 cells were labelled with CD133/1 antibody conjugated to a magnetic microbead (Miltenyi Biotec) and separated into CD133/1-positive and negative populations. The negative cells were subcultured under normoxic and hypoxic conditions then harvested at 24, 48 and 72-h time points to analyse CD133/1 expression by flow cytometry.

Statistics. Statistical evaluation was carried out by Student's t-test for qRT-PCR and flow cytometry data analysis. A p-value of $<0.05$ was taken as significant.

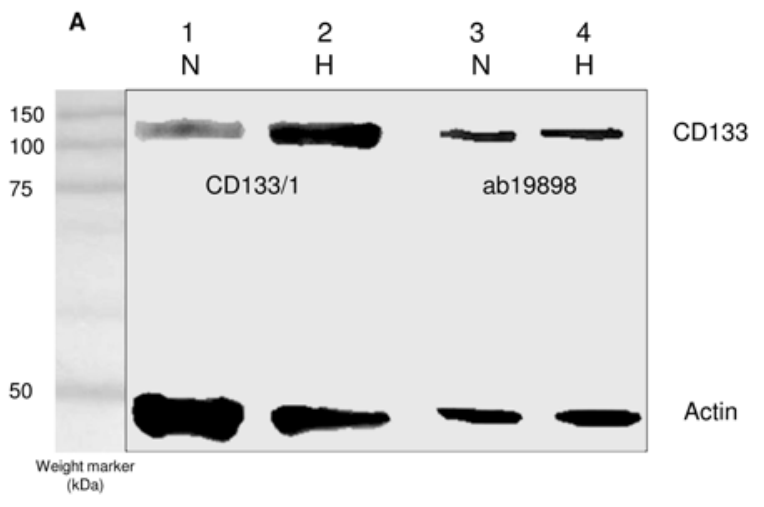

B

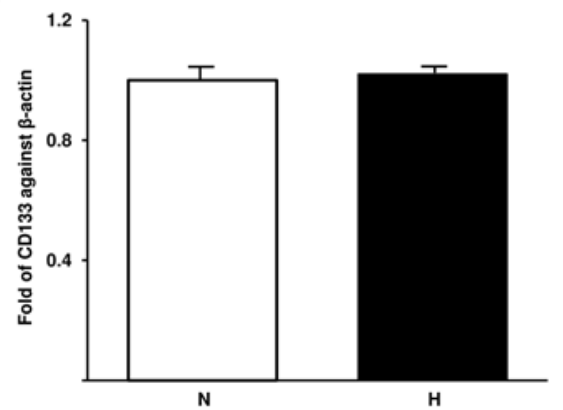

Figure 2. Analysis of CD133 expression in IN699 cells. A, Western blotting with CD133/1 and ab19898. All lanes show actin around the expected $48 \mathrm{kDa}$ marker and CD133 around $120 \mathrm{kDa}$. Lanes 1 and 2, CD133/1 for normoxic (N) and hypoxic $(\mathrm{H})$ cell lysates; lanes 3 and 4, ab19898 for normoxic and hypoxic cell lysates. B, qRT-PCR detection of CD133 mRNA level in normoxic (N) and hypoxic (H) IN699 cells when normalised against the internal control $\beta$-actin. Error bars indicate the standard deviation.

\section{Results}

Analysis of CD133 expression by WB and qRT-PCR. WB was used to semi-quantitatively determine the presence of CD133 in normoxic and hypoxic cells. The blot was probed with ab19898 


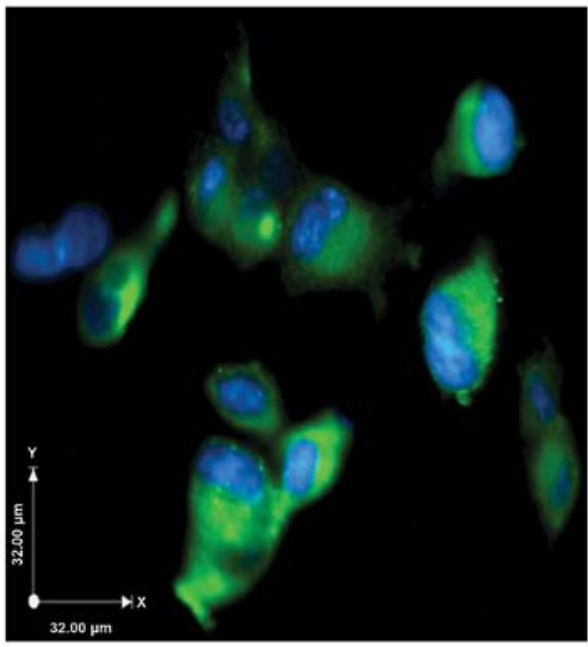

ab19898

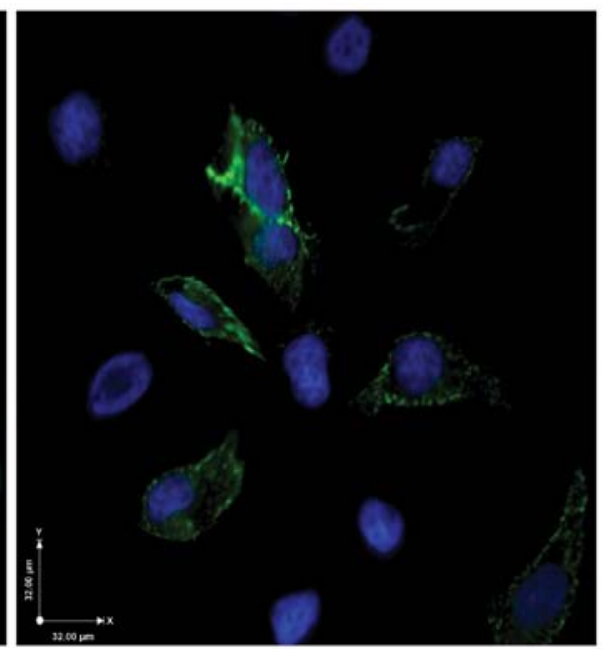

CD133/1

Figure 3. Representative ICC images of CD133 staining in IN699 cells (scale bar, $32 \mu \mathrm{m}$ ). Nucleus is stained blue with DAPI (4',6-diamidino-2-phenylindole); the primary antibodies ab19898 and CD133/1 were visualised by green-fluorescence (AlexaFluor-488).

A

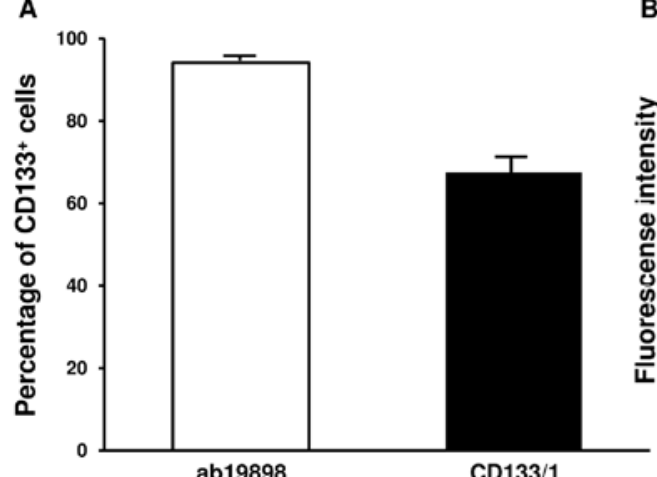$$
\text { C }
$$

B

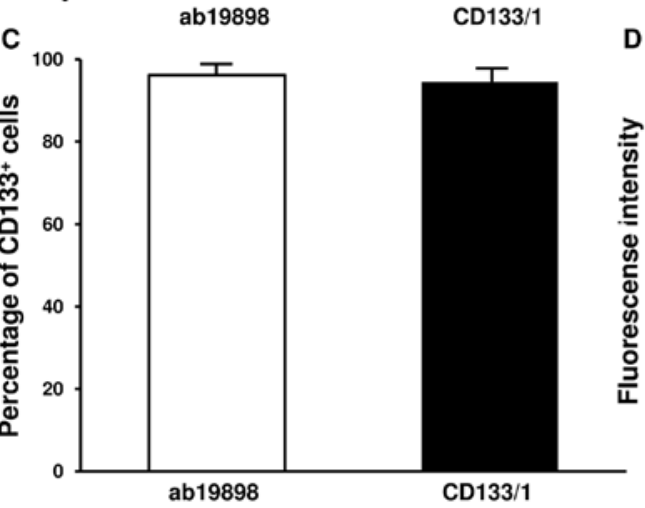

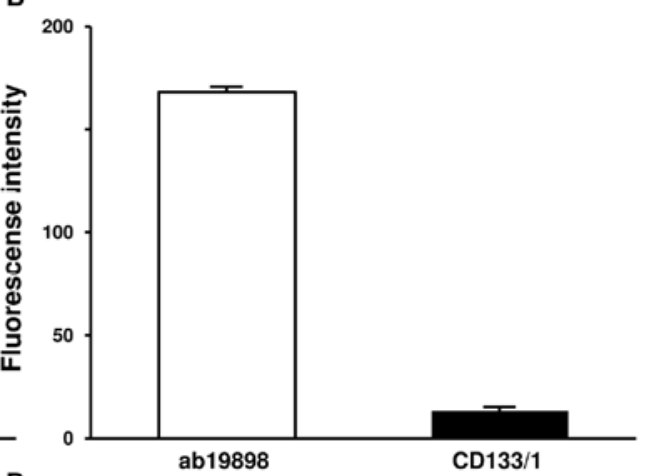

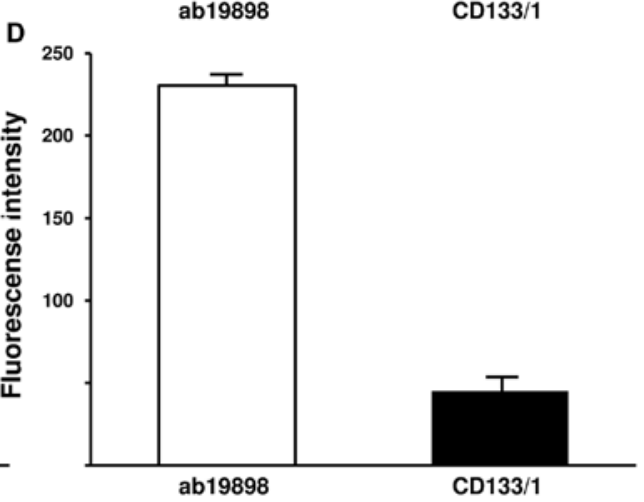

Figure 4. Comparison of MFI and GFI between CD133/1 and ab19898. A and B, MFI and GFI of both antibodies detected in normoxic IN699 cells; C and D, MFI and GFI of both antibodies detected in hypoxic IN699 cells. Error bars indicate the standard deviation.

and CD133/1 (W6B3C1) for CD133 detection and actin was used as a control (Fig. 2A). Comparison between CD133 bands detected with CD133/1 indicates an increase in glycosylated CD133 under hypoxic conditions whereas ab19898 detected similar amounts of CD133 under both conditions. The expression of CD133 was further investigated at mRNA level using qRT-PCR. In accordance with WB, CD133 mRNA was detected at similar levels in both normoxic and hypoxic cells when CD133 expression was normalised against that of the internal control gene, $\beta$-actin ( $p=0.343$; Fig. $2 B$ ).
Immunostaining of CD133. ICC images demonstrated the intracellular staining by ab19898 whereas CD133/1 stained extracellularly giving a clear outline of the cells (Fig. 3).

Quantification of CD133 by flow cytometry. The IN699 cells were further characterised with CD133/1 (AC133) and ab19898 antibodies by flow cytometry to establish the percentage of $\mathrm{CD}_{133}{ }^{+}$cells by the MFI (mean fluorescence intensity) and the average expression level of the protein in individual cells by GFI (geomean fluorescence intensity). In accordance with 
previous data (14), CD133/1 detected $67.5 \%$ and $94.5 \%$ of $\mathrm{CD}_{133}{ }^{+}$cells under normoxic and hypoxic culture conditions respectively (Fig. 4A and C; $<<0.005$ ). The GFI associated with the antigen binding sites significantly increased in hypoxia (Fig. 4B and D; p<0.005). On the contrary, flow cytometry with ab19898 showed a similar percentage of CD133+ cells under both culture conditions (Fig. 4A and C; p=0.157). Similarly, no significant difference was demonstrated by GFI (Fig. 4B and $\mathrm{D} ; \mathrm{p}=0.0844$ ). Compared with CD133/1, ab19898 detected a higher percentage of $\mathrm{CD}_{133^{+}}$cells as well as a much stronger expression level of the protein per cell in normoxic IN699 cells (Fig. 4A and B; p<0.005). Interestingly, under hypoxic conditions, both antibodies detected a similar positive proportion as indicated by MFI $(\mathrm{p}=0.0786)$ whereas GFI suggested that a significant increase in the average expression level of CD133 was present using ab19898 ( $\mathrm{p}<0.005$ ) (Fig. 4C and D).

In order to further investigate the effect of oxygen tension on CD133 glycosylation status, CD133/1-negative IN699 cells were sorted by the autoMACS technique and cultured under normoxic and hypoxic conditions over the period of 24,48 and $72 \mathrm{~h}$. Cells were then analysed by flow cytometry using CD133/1 antibody. Interestingly, $48.0 \%, 17.9 \%$ and $29.4 \%$ of the 'negative' population were detected as positive respectively at each time point within the normoxic cell group, using the same antibody used for cell sorting, i.e., CD133/1. There was no obvious difference in GFI amongst the time points, with the average value of $8.79(\mathrm{p}=0.422)$ (data not shown). Under hypoxic conditions, $49.7 \%, 36.1 \%$ and $40.8 \%$ of the 'negative' population were detected positive respectively, with the average GFI of 8.48 $(\mathrm{p}=0.357)$ (data not shown). Thus, at 48 and 72-h hypoxia was shown to strongly promote the glycosylation status of CD133.

\section{Discussion}

Collectively, our WB and qRT-PCR data suggest that CD133 is constitutively expressed while flow cytometry results indicate that the glycosylation status of the protein is enhanced by hypoxia. Furthermore, glycosylation of CD133 fluctuates during in vitro culture under both normoxic and hypoxic conditions. Previous studies using CD133/1 under normoxic conditions may have only detected a fraction of CD133-expressing cells, implying that the previously categorised CD133- cells with tumour-initiating properties may have actually been undetected $\mathrm{CD}_{133^{+}}$cells. Our flow cytometry data indicate that a constitutive expression of CD133 exists in IN699 cells regardless of oxygen stress but CD133 glycosylation is enhanced by oxygen depletion although only a small proportion of the protein is glycosylated in individual cells. This could be that the machinery producing and moving mature molecules to the surface is saturated or that there is only a certain amount of glycosylated CD133 on the cell membrane at any given time.

In order to study $\mathrm{CD} 133^{+}$cells as BTSCs their behaviour must be investigated under conditions close to those in vivo. Analysing CD133+ cells under hypoxic conditions, as in this study, advances knowledge in this field. The broadly used CD133/1 antibody has been shown in this study to rely on the glycosylation status of CD133, which in normoxia would yield a much lower population of $\mathrm{CD} 133^{+}$cells than in hypoxia. This study supports the results that hypoxia elevates the number of CD133+ cells (17), although the connection with shortcomings of the CD133/1 antibody approach was not made in previous studies. Such studies have also failed to show whether the total amount of CD133 expressed per cell increases under hypoxic conditions, irrespective of glycosylation status. This could have been demonstrated effectively if a non-glycosylation dependent antibody like ab19898 had been used, as our data suggest that although hypoxia enhances CD133 glycosylation, a proportion of the molecule remains unglycosylated in the CD133-expressing IN699 cells. Therefore this study shows that the immunodetection of CD133 using CD133/1 is affected by glycosylation status of the protein, providing an explanation for the previous contradictory results regarding tumourigenic properties of $\mathrm{CD}_{133^{+}}$and $\mathrm{CD} 133^{-}$cells $(2,3)$.

The present study also questions the widely used CD133/1 as the antibody of choice to isolate entire $\mathrm{CD} 133^{+}$populations, although CD133/1 may still be useful in elucidating the biological function of the glycosylated CD133. Based on our observations, ab19898 should be more effective than CD133/1 in enriching $\mathrm{CD}_{133^{+}}$cells in glioma, be they CSCs or not, as the former is not only glycosylation-independent, but also binds the intracellular, and thus probably immature, protein in cells that may not be expressing cell surface CD133 at the time. Moreover, different splice variants of CD133 may have different glycosylation patterns and it is unknown how this could affect the immunological detection of CD133 using glycosylation-dependent antibodies (22). The suggestion that CD133/1 has limitations in detecting CD133 is supported by findings that the AC133 epitope recognised by CD133/1 is lost during cancer stem cell differentiation, although the expression level of CD133 protein remains the same (23), as well as by a recent study in which a truncated variant of the protein was detected in glioblastoma cells negative for CD133/1 antibody (9). On the other hand, the glycosylated CD133 protein on the cell surface is more likely to be mature with defined biological function and capability of interacting with extracellular messenger molecules (24), e.g., the ganglioside GD3 which is overexpressed on glioma cells and plays important regulatory roles in apoptosis and invasion $(25,26)$. Therefore CD133/1 could be valuable in elucidation of the functional significance of CD133 glycosylation and its impact on CSC biology, filling the knowledge gap surrounding glycosylation patterns during cell proliferation and differentiation.

To our knowledge, this is the first time that hypoxia has been shown to enhance CD133 glycosylation, although hypoxiainduced CD133 expression has been demonstrated previously (14-17,27). Although a previous study using tissue sections of glioma revealed differences in CD133 expression based upon antibody used (19), ours is the first study whereby the defined population of $\mathrm{CD} 33^{+}$or $\mathrm{CD} 133^{-}$glioblastoma cells was used to establish the influence of hypoxic conditions on CD133 glycosylation using different antibodies. Moreover, it is known that hypoxia promotes cancer cell invasion and distant metastasis, including that in gliomas (28-30), and recently upregulation of CD133 under hypoxic conditions has also been associated with increased aggressiveness of pancreatic cancer cells (31). In addition, the critical roles that mitochondria play in cancer development and progression have long been recognised (32-35) and accumulating evidence supports the 'cross-talking' relationship between mitochondria and HIF-1 in protecting cancer cells from hypoxia-mediated apoptosis (36-40). Therefore, based on 
studies by us and other researchers, we hypothesise that glycosylated CD133 may interact with GD3 (as mentioned above) and/or other unknown modulators to promote glioma stem cell survival and invasiveness during hypoxia-triggered apoptosis, mediated by signal pathways involving HIF- $1 \alpha$ and mitochondria $(16,25-$ 27,36-42). This hypothetic involvement of glycosylated CD133 in the 'pro-survival' feature of hypoxic CSCs is further mirrored by observations where CD133-positive cells show enhanced resistance against pro-apoptotic chemotherapy drugs $(43,44)$.

Furthermore, it is unlikely that there is one ideal CSC marker which can be detected on all cells at any given time and under any condition. In the case of CD133, rather than evaluating it as a CSC marker, it might be more pertinent to understand its biological function in tumour development and progression.

\section{Acknowledgements}

The authors wish to express their gratitude for support of this work by Ali's Dream, Brainstrust, Brain Tumour Research, Brain Tumour UK and Charlie's Challenge.

\section{References}

1. Singh SK, Clarke ID, Terasaki M, Bonn VE, Hawkins C, Squire J and Dirks PB: Identification of a cancer stem cell in human brain tumours. Cancer Res 63: 5821-5828, 2003.

2. Wang J, Sakariassen PØ, Tsinkalovsky O, Immervoll H, Bøe SO, Svendsen A, Prestegarden L, Røsland G, Thorsen F, Stuhr L, Molven A, Bjerkvig R and Enger PØ: CD133 negative glioma cells form tumors in nude rats and give rise to CD133 positive cells. Int J Cancer 122: 761-768, 2008.

3. Clément V, Dutoit V, Marino D, Dietrich PY and Radovanovic I: Limits of CD133 as a marker of glioma self-renewing cells. Int J Cancer 125: 244-248, 2009.

4. Mizrak D, Brittan M and Alison MR: CD133: molecule of the moment. J Pathol 214: 3-9, 2008.

5. Cheng JX, Liu BL and Zhang X: How powerful is CD133 as a cancer stem cell marker in brain tumors? Cancer Treat Rev 35: 403-408, 2009.

6. Campos B and Herold-Mende CC: Insight into the complex regulation of CD133 in glioma. Int J Cancer 128: 501-510, 2011.

7. Sun Y, Kong W, Falk A, Hu J, Zhou L, Pollard S and Smith A: CD133 (prominin) negative human neural stem cells are clonogenic and tripotent. PLoS One 4: 1-10, 2009.

8. Fargeas CA, Huttner WB and Corbeil D: Nomenclature of prominin-1 (CD133) splice variants - an update. Tissue Antigens 69: 602-606, 2007.

9. Osmond TL, Broadley KW and McConnell MJ: Glioblastoma cells negative for the anti-CD133 antibody AC133 express a truncated variant of the CD133 protein. Int J Mol Med 25: 883-888, 2010.

10. Bidlingmaier S, Zhu X and Liu B: The utility and limitations of glycosylated human CD133 epitopes in defining cancer stem cells. J Mol Med 86: 1025-1032, 2008.

11. Oliver L, Olivier C, Marhuenda FB, Campone M and Vallette FM: Hypoxia and the malignant glioma microenvironment: regulation and implications for therapy. Curr Mol Pharmacol 2: 263-284, 2009.

12. Evans SM, Judy KD, Dunphy I, Jenkins WT, Hwang WT, Nelson PT, Lustig RA, Jenkins K, Magarelli DP, Hahn SM, Collins RA, Grady MS and Koch CJ: Hypoxia is important in the biology and aggression of human glial brain tumors. Clin Cancer Res 10: 8177-8184, 2004.

13. Amberger-Murphy V: Hypoxia helps glioma to fight therapy. Curr Cancer Drug Targets 9: 381-390, 2009.

14. Donovan LK, Potter NE, Warr T and Pilkington GJ: A Prominin-1rich paediatric glioblastoma: biological behaviour is determined by oxygen tension modulated CD133 expression but not accompanied by underlying molecular profiles. Transl Oncol 5: 141-154, 2012.

15. McCord AM, Jamal M, Shankavaram UT, Lang FF, Camphausen $K$ and Tofilon PJ: Physiologic oxygen concentration enhances the stem-like properties of $\mathrm{CD} 133^{+}$human glioblastoma cells in vitro. Mol Cancer Res 7: 489-497, 2009.
16. Griguer CE, Oliva CR, Gobin E, Marcorelles P, Benos DJ, Lancaster JR Jr and Gillespie GY: CD133 is a marker of bioenergetic stress in human glioma. PLoS One 3: e3655, 2008.

17. Platet N, Liu SY, Atifi ME, Oliver L, Vallette FM, Berger F and Wion D: Influence of oxygen tension on CD133 phenotype in human glioma cell cultures. Cancer Lett 258: 286-290, 2007.

18. Iida H, Suzuki M, Goitsuka R and Ueno H: Hypoxia induces CD133 expression in human lung cancer cells by up-regulation of OCT3/4 and SOX2. Int J Oncol 40: 71-79, 2012.

19. Hermansen SK, Christensen KG, Jensen SS and Kristensen BW: Inconsistent immunohistochemical expression patterns of four different CD133 antibody clones in glioblastoma. J Histochem Cytochem 59: 391-407, 2011.

20. Günther HS, Schmidt NO, Phillips HS, Kemming D, Kharbanda S, Soriano R, Modrusan Z, Meissner H, Westphal M and Lamszus K: Glioblastoma-derived stem cell-enriched cultures form distinct subgroups according to molecular and phenotypic criteria. Oncogene 27: 2897-2909, 2008.

21. An Q, Burke GA, Dainton M, Harrison CJ, Kempski H, Konn Z, Myooren W, Stewart A, Taj M, Webb D, Strefford JC and Martineau M: Haploinsufficiency of the MLL and TOB2 genes in lymphoid malignancy. Leukemia 24: 649-652, 2010.

22. Fargeas CA, Fonseca A, Huttner WB and Corbeil D: Prominin-1 (CD133): from progenitor cells to human diseases. Future Lipidology 1: 213-255, 2006.

23. Kemper K, Sprick MR, De Bree M, Vermeulen L, Hoek M, Zeilstra J, Pals ST, Mehmet H, Stassi G and Medema JP: The $\mathrm{AC} 133$ epitope, but not the CD133 protein, is lost upon cancer stem cell differentiation. Cancer Res 70: 719-729, 2010.

24. Gahmber CG and Tolvanen M: Why mammalian cell surface proteins are glycoproteins. Trends Biochem Sci 21: 308-311, 1996.

25. Taïeb N, Maresca M, Guo X, Garmy N, Fatini J and Yahi N: The first extracellular domain of the tumour stem cell marker CD133 contains an antigenic ganglioside-binding motif. Cancer Lett 278: 164-173, 2009.

26. Birks SM, Danquah JO, King L, Vlasak R, Gorecki DC and Pilkington GJ: Targeting the GD3 acetylation pathway selectively induces apoptosis in glioblastoma. Neuro Oncol 13: 950-960, 2011.

27. Bar EE, Lin A, Bar EE, Lin A, Mahairaki V, Matsui $\mathrm{W}$ and Eberhart CG: Hypoxia increases the expression of stem-cell markers and promotes clonogenicity in glioblastoma neurospheres. Am J Pathol 177: 1491-1502, 2010.

28. Ruan K, Song G and Ouyang G: Role of hypoxia in the hallmarks of human cancer. J Cell Biochem 107: 1053-1062, 2009.

29. Lu X and Kang Y: Hypoxia and hypoxia-inducible factors: master regulators of metastasis. Clin Cancer Res 16: 5928-5935, 2010.

30. Fujiwara S, Nakagawa K, Harada H, Nagato S, Furukawa K, Teraoka M, Seno T, Oka K, Iwata S and Ohnishi T: Silencing hypoxia-inducible factor-1alpha inhibits cell migration and invasion under hypoxic environment in malignant gliomas. Int $\mathbf{J}$ Oncol 30: 793-802, 2007.

31. Hashimoto O, Shimizu K, Semba S, Chiba S, Ku Y, Yokozaki H and Hori Y: Hypoxia induces tumor aggressiveness and the expansion of CD133-positive cells in a hypoxia-inducible factor- $1 \alpha$ dependent manner in pancreatic cancer cells. Pathobiology 78: 181-192, 2011

32. Lee HC and Wei YH: Mitochondrial DNA instability and metabolic shift in human cancers. Int J Mol Sci 10: 674-701, 2009.

33. Gogvadze V, Zhivotovsky B and Orrenius S: The Warburg effect and mitochondrial stability in cancer cells. Mol Aspects Med 31: 60-74, 2010.

34. Grandemange S, Herzig S and Martinou JC: Mitochondrial dynamics and cancer. Semin Cancer Biol 19: 50-56, 2009.

35. Ishikawa $K$ and Hayashi J: A novel function of mtDNA: its involvement in metastasis. Ann NY Acad Sci 1201: 40-43, 2010.

36. Denko NC: Hypoxia, HIF1 and glucose metabolism in the solid tumour. Nat Rev Cancer 8: 705-713, 2008.

37. Semenza GL: Regulation of cancer cell metabolism by hypoxiainducible factor 1. Semin Cancer Biol 19: 12-16, 2009.

38. Chiche J, Rouleau M, Gounon P, Brahimi-Horn MC, Pouysségur J and Mazure NM: Hypoxic enlarged mitochondria protect cancer cells from apoptotic stimuli. J Cell Physiol 222: 648-657, 2010.

39. Klimova T and Chandel NS: Mitochondrial complex III regulates hypoxic activation of HIF. Cell Death Differ 15: 660-666, 2008.

40. De Haan C, Habibi-Nazhad B, Yan E, Salloum N, Parliament M and Allalunis-Turner J: Mutation in mitochondrial complex I ND6 subunit is associated with defective response to hypoxia in human glioma cells. Mol Cancer 3: 19, 2004. 
41. Soeda A, Park M, Lee D, Mintz A, Androutsellis-Theotokis A, McKay RD, Engh J, Iwama T, Kunisada T, Kassam AB, Pollack IF and Park DM: Hypoxia promotes expansion of the CD133-positive glioma stem cells through activation of HIF-1alpha. Oncogene 28: 3949-3959, 2009.

42. Lluis JM, Llacuna L, von Montfort C, Bárcena C, Enrich C, Morales A and Fernandez-Checa JC: GD3 synthase overexpression sensitizes hepatocarcinoma cells to hypoxia and reduces tumor growth by suppressing the $\mathrm{cSrc} / \mathrm{NF}-\mathrm{kappaB}$ survival pathway. PLoS One 4: e8059, 2009.
43. Kolenda J, Jensen SS, Aaberg-Jessen C, Christensen K, Andersen C, Brünner N and Kristensen BW: Effects of hypoxia on expression of a panel of stem cell and chemoresistance markers in glioblastoma-derived spheroids. J Neurooncol 103: 43-58, 2011.

44. Cortes-Dericks L, Carboni GL, Schmid RA and Karoubi G: Putative cancer stem cells in malignant pleural mesothelioma show resistance to cisplatin and pemetrexed. Int J Oncol 37: 437-444, 2010. 